\title{
Maternal methyl supplemented diets and effects on offspring health
}

\author{
Rachel J. O'Neill ${ }^{1,2}$, Paul B. Vrana ${ }^{3,4}$ and Cheryl S. Rosenfeld ${ }^{5,6,7 *}$ \\ ' Department of Molecular and Cell Biology, University of Connecticut, Storrs, CT, USA \\ 2 Institute for Systems Genomics, University of Connecticut, Storrs, CT, USA \\ ${ }^{3}$ Peromyscus Genetic Stock Center, University of South Carolina, Columbia, SC, USA \\ ${ }^{4}$ Department of Biological Sciences, University of South Carolina, Columbia, SC, USA \\ ${ }^{5}$ Department of Biomedical Sciences, Bond Life Sciences Center, University of Missouri, Columbia, MO, USA \\ ${ }^{6}$ Bond Life Sciences Center, University of Missouri, Columbia, MO, USA \\ 7 Genetics Area Program Faculty Member, Bond Life Sciences Center, University of Missouri, Columbia, MO, USA
}

\section{Edited by:}

Trygve Tollefsbol, University of

Alabama at Birmingham, USA

\section{Reviewed by:}

Craig A. Cooney, Central Arkansas Veterans Healthcare System, USA Simonetta Friso, University of Verona School of Medicine, Italy

\section{*Correspondence:}

Cheryl S. Rosenfeld, Biomedical Sciences and Bond Life Sciences Center, University of Missouri, 440F Bond Life Sciences Center, 1201 E. Rollins Rd., Columbia, MO 65211, USA

e-mail: rosenfeldc@missouri.edu
Women seeking to become pregnant and pregnant women are currently advised to consume high amounts of folic acid and other methyl donors to prevent neural tube defects in their offspring. These diets can alter methylation patterns of several biomolecules, including nucleic acids, and histone proteins. Limited animal model data suggests that developmental exposure to these maternal methyl supplemented (MS) diets leads to beneficial epimutations. However, other rodent and humans studies have yielded opposing findings with such diets leading to promiscuous epimutations that are likely associated with negative health outcomes. Conflict exists to whether these maternal diets are preventative or exacerbate the risk for Autism Spectrum Disorders (ASD) in children. This review will discuss the findings to date on the potential beneficial and aversive effects of maternal MS diets. We will also consider how other factors might influence the effects of MS diets. Current data suggest that there is cause for concern as maternal MS diets may lead to epimutations that underpin various diseases, including neurobehavioral disorders. Further studies are needed to explore the comprehensive effects maternal MS diets have on the offspring epigenome and subsequent overall health.

Keywords: DNA methylation, diet, DOHaD, maternal, in utero, nutrition, nutriceutical

\section{INTRODUCTION}

Mounting evidence suggests that developmental exposure to extrinsic factors (e.g., diet, chemical exposure, and stress) leads to pronounced epigenetic and phenotypic effects, commonly referred to as the "developmental origin of health and disease (DOHaD)" (Barker, 1997; Hanson and Gluckman, 2011; Barouki et al., 2012; Rosenfeld, 2012). Epigenetic changes are meiotically and mitotically heritable and include DNA methylation, histone protein modifications, chromatin re-arrangement, and non-coding RNAs (Rosenfeld, 2010).

Methylation of $\mathrm{CpG}$ sites is a potent regulator of gene expression, and this process is affected by various external, including dietary, factors. There has been growing interest in the potential protective effects that dietary supplements might exert on these epigenetic marks. Such nutraceuticals include molecules that directly lend methyl donors in the methyl activation cycle or serve as cofactors in these pathways, such as methionine, pyridoxine (vitamin B6), folate (vitamin B9), betaine (trimethylglycine), choline, Vitamin $B_{12}$, and zinc (Figure 1). Many of these compounds are included in periconceptional/ prenatal vitamins, due to their ability to prevent neural-tube and other CNS defects in developing fetuses and other health benefits. While all of these factors exert key roles, emphasis has been placed on folic acid, wherein women are recommended to consume a multivitamin containing $0.8 \mathrm{mg}$ of folic acid 1 month prior to conception and throughout the first few months of pregnancy (http://www.uspreventiveservicestaskforce.org/uspstf/ uspsnrfol.htm; Wolff et al., 2009a,b; Steenblik et al., 2011).

Animal model studies have examined how maternal methyl supplemented (MS) diets impact the epigenome and/or phenotypic outcomes in developing offspring (Table 1A). Some of these studies have reported favorable effects of these diets on overall health. Other studies, though, have reported detrimental maternal MS alterations. Limited studies have examined linkages between maternal MS diets and epimutations/disease in her children (Table 1B).

Other factors likely interact with maternal diet to influence the net effect of these diets. Examples include genetic background, sex, developmental windows of exposure, and tissue/cell-specific vulnerabilities, which are discussed below.

\section{MATERNAL METHYL SUPPLEMENTED DIETS AND OUTCOMES IN ANIMAL MODEL STUDIES}

One of the first reports linking environmental exposure to epimutations suggested that for a specific genotype ( $A^{v y} / a$ offspring), pregnant $a / a$ female mice exposed to the endocrine disrupting compound (EDC) bisphenol A (BPA) gave birth to a greater percentage of yellow coat color compared to brown coat color 


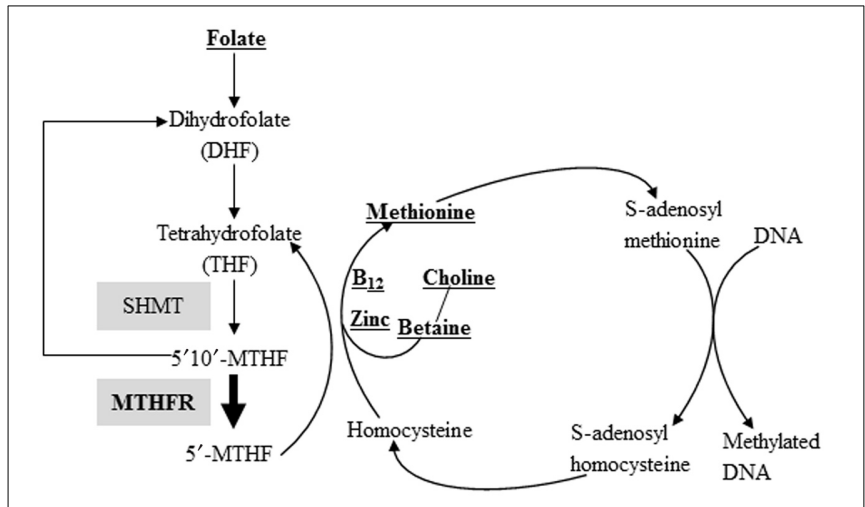

FIGURE 1 | Nutritional methyl-supplements and the DNA methylation reaction. Methyl groups, either synthesized via the folate cycle or donated directly from betaine, are activated by the methyl activation cycle. Activated methyl groups are used to methylate cytosine residues of DNA. Both vitamin $B_{12}$ and zinc are cofactors used in the transfer of methyl groups. Compounds listed in bold and underlined are methyl donors or cofactors included in various methyl supplemented diets. Select enzymes involved in this pathway, including MTHFR, where single nucleotide polymorphisms (SNP) variant genotypes have been documented (as detailed in the manuscript) are shaded.

( $\left.A^{v y} / a\right)$ offspring (Dolinoy et al., 2007), although we were not able to reproduce these BPA-induced results (Rosenfeld et al., 2013). Nonetheless, this first report indicated that offspring of both BPAexposed and control animals are genetically identical but differ epigenetically in the DNA methylation status in at least one allele, $A^{v y}$, encoding for the agouti signaling protein (ASIP) (Dolinoy et al., 2007). Humans do not possess this allele, but ASIP is abundantly expressed in human adipose tissue and pancreas, where it has been linked with obesity and type 2 diabetes (Mynatt and Stephens, 2001; Voisey and Van Daal, 2002).

When the cryptic promoter derived from the retroviral intracisternal A particle (IAP) within this allele is hypomethylated, $A^{v y}$ is expressed ectopically and constitutively resulting in yellow coat color mice who are prone to developing these metabolic disorders. In contrast, if the IAP promoter remains methylated, it is non-functional, leading to pseudoagouti (brown) coat color animals that are concomitantly less prone to these adult diseases. Combined prenatal treatment with a BPA and methyl-supplemented diet in these females was reported to offset the BPA-induced shift in coat color distribution from metabolic deleterious yellow morphs to an increase in brown coat color, healthier offspring (Dolinoy et al., 2007). Earlier reports indicated that $a / a$ females harboring $A^{v y} / a$ who were fed a methyl-enriched diet 2 weeks prior to conception through weaning gave birth to a greater percentage of brown coat color offspring (Wolff et al., 1998; Cooney et al., 2002; Waterland and Jirtle, 2003).

Methyl diet supplementation can interact with epigenotype ( $A^{v y} / \mathrm{a}$ status) over several generations (through $\mathrm{F}_{5}$ ) to increase percentage of pseudoagouti animals possessing a methylated IAP promoter site (Cropley et al., 2012). However, removal of MS in later generations led to reversal of this phenotypic distortion. While a MS diet did not increase 5-methylcytosine levels over six generations in $\mathrm{C} 57 \mathrm{Bl} 6 \mathrm{~J}$ mice, this diet increased the stochastic epigenetic variation in several loci with effects becoming more pronounced in later generations on this diet $(\mathrm{Li}$ et al., 2011). Combined results suggest that MS diets lead to epigenetic variability over time and may account for altered disease risk, although no harmful multigenerational phenotypic effects were reported in C57B16J or $A^{v y} / a$ mice (Li et al., 2011; Cropley et al., 2012).

Mice deficient for twisted gastrulation (TWSG1), an extracellular modulator of bone morphogenetic protein signaling, exhibit midline facial and jaw defects. However, maternal MS diet prevented their jaw defects (Billington et al., 2013). Similarly, a maternal MS diet alleviated atherosclerosis in ApoE homozygous mutant mice and corresponding elevation of $\mathrm{Ccr} 2$, production of inflammatory cytokines, and restoration of the HDL to LDL ratio (Delaney et al., 2013). Maternal choline supplementation of mice has also been reported to abolish transcriptional defects in genes related to cell growth and metabolism and reduced weaning body weight that are typically observed in fetal toxic milk (tx-j) mice, a model of Wilson Disease (an autosomal recessive disorder leading to hepatic copper accumulation) (Medici et al., 2014). This maternal supplement may also improve spatial mapping and basal forebrain cholinergic neuron numbers in Ts65Dn mice (Ash et al., 2014).

Combined treatment of pregnant rodent dams with methyl supplements has been reported to mitigate harmful effects of a high fat diet, including metabolic, select behavioral, DNA methylation, and gene expression effects (Carlin et al., 2013). Maternal MS may also reverse alcohol-induced DNA methylation Igf2 changes (Downing et al., 2011).

Maternal MS diet in rats resulted in decreased offspring concentration of leptin and hypermethylation of the leptin $(O b)$ promoter (Giudicelli et al., 2013). Both offspring sexes exhibited impaired post-natal growth, and males showed increased long-term body weight gain.

No animal model study to date, however, has considered the long-term impact of exposure to these supplements. Moreover, current diet recommendations are based on the premise that many diseases are triggered by hypomethylation of discrete CpG sites. However, only two animal models to date have linked epimutations in DNA methylation to maternal MS diet exposure: viable yellow mice $\left(A^{v y} / a\right)$ with metabolic disorders, discussed above, and $A x i n^{F u}$ mice exhibiting tail dysmorphogenesis, or "kinky" tail (Waterland et al., 2006; Rosenfeld, 2010). Both examples are the result of DNA methylation alteration in a specific gene-embedded retroviral particle, IAP. It is unlikely that consumption or maternal exposure to MS selectively targets a single locus within the genome. Instead, such nutritional supplements may induce widespread and promiscuous effects. The developing fetus is especially vulnerable to these changes, as this is when there is re-establishment of new epigenetic marks and programming of the primordial germ cells. It is thus not surprising that there are also mounting animal model studies reporting deleterious effects in offspring born to dams on a MS diet.

Combined exposure of mouse fetuses to arsenic and maternal MS, in the form of folate, led to more pronounced DNA methylation changes in the liver and corresponding impaired fetal development and body weight gain (Tsang et al., 2012). 
Maternal folic acid supplementation along with a high fat diet increased glucose intolerance and insulin resistance in male mice offspring (Huang et al., 2014). Another study in mice indicated that a maternal MS diet resulted in harmful and persistent changes in offspring gut microbiota populations, colonic mucosal DNA methylation, and gene expression changes, and increased incidence of colitis compared to control offspring (Schaible et al., 2011). A similar maternal dietary regimen increased the incidence of allergic airway disease in mice with corresponding hypermethylation of Runx3, a gene that suppresses allergic airway disease (Hollingsworth et al., 2008). This same maternal diet suppressed proinflammatory signals in mice (Delaney et al., 2012).

Treatment of rat dams fed a methyl donor, choline supplemented, or deficient diet resulted in selective fetal DNA methylation and histone protein marks (Davison et al., 2009). A maternal choline deficient diet resulted in hypermethylation of fetal $G 9 a$ and Suv39h1 relative to controls. Coincident with this hypermethylation, modified histones associated with transcriptional silencing, $\mathrm{H} 3 \mathrm{~K} 9 \mathrm{Me} 2$ and $\mathrm{H} 3 \mathrm{~K} 27 \mathrm{Me} 3$, increased with maternal choline supplementation. In contrast, the histone mark associated with active promoters, $\mathrm{H} 3 \mathrm{~K} 4 \mathrm{Me} 2$, surged in expression with the choline-deficient maternal diet.

Gestational and postnatal exposure (in case of pup assessments) to high concentrations of folic acid resulted in newborn mouse pups exhibiting disrupted cerebral gene expression for transcripts and their protein products implicated in normal neural development (Barua et al., 2014). These maternal MS pups also exhibited behavioral alternations (increased ultrasonic vocalizations, heightened anxiety-like, and hyperactive behaviors).

\section{HUMAN EPIDEMIOLOGICAL STUDIES LINKING MATERNAL MS DIETS AND OFFSPRING EPIMUTATIONS}

Increased maternal intake during the periconceptional period of choline was inversely correlated with umbilical cord blood methylation of her sons (Boeke et al., 2012). Consumption of folic acid supplements by pregnant women after 12 weeks of gestation has been linked to epigenetic changes in fetal cord blood, including increased methylation of the paternally expressed IGF2 gene and decreased methylation of the similarly imprinted PEG3, as well as LINE-1s (Haggarty et al., 2013). These results thus suggest that a maternal MS diet can influence expression of both repeat elements and imprinted genes in offspring. The long term phenotypic effects of such changes, however, remain unknown. In women, maternal folic acid supplementation has been linked to decreased incidence of preeclampsia and small for gestational age births (Kim et al., 2014). On the other hand, maternal supplementation of folic acid beginning at the first trimester increased the likelihood of infant bronchiolitis (Veeranki et al., 2014).

A recent study of Gambian women and their children demonstrated that consumption of a methyl enriched diet during pregnancy strongly correlated with persistent and systemic epigenetic changes in several metastable epialleles in offspring (DominguezSalas et al., 2014). This relatively large (24 villages, 166 women), 2 years study suggests a strong association between maternal methyl donor consumption and DNA methylation patterns in the genomes of offspring, which may ultimately result in adverse phenotypic outcomes.

\section{LINKAGE OF MATERNAL METHYL SUPPLEMENTED DIETS AND PREVENTION/RISK FOR ASD IN HER CHILDREN}

Although maternal supplementation with folic acid and other methyl donors contained within pre-natal vitamins has been promoted as a protection against Autism Spectrum Disorders (ASD) in children (Schmidt et al., 2011, 2012), other studies suggest an opposite correlation (Rogers, 2008; Leeming and Lucock, 2009; Beard et al., 2011). The study suggesting that maternal MS diets prevented ASD was based on a cohort population of 288 children that ranged from 24 to 60 months of age and found an associated greater risk for ASD in children of mothers who did not consume prenatal vitamins supplemented with methyl components during the periconceptional period (Schmidt et al., 2011). A follow-up study by this same group further suggested that consumption of folic acid by women beginning at the periconceptional period may reduce the risk for ASD in mothers and children with inefficient folate metabolism, i.e., a single nucleotide polymorphism (SNP) in methylenetetrahydrofolate reductase (MTHFR $677 \mathrm{C}>\mathrm{T}$ variant genotype). This enzyme catalyzes the conversion of 5,10-methylenetetrahydrofolate $\left(5^{\prime}, 10\right.$, '-MTHF) to 5-methyltetrahydrofolate ( 5 -MTHF, Figure 1) and is thus the rate-limiting enzyme in the methyl cycle (Schmidt et al., 2012).

In contrast, a study that employed ASD incidence rates from the Rochester Epidemiological Project in Rochester, MN, which spanned decades from 1976-1997, suggested a strong correlation (0.87) for maternal consumption of prescription prenatal vitamins (containing $>1 \mathrm{mg}$ of folic acid) and ASD incidence in offspring (Beard et al., 2011). Consequently, the investigators concluded that too much folic acid might disrupt brain development and thus increase the risk for ASD, a hypothesis promoted in previous studies (Rogers, 2008; Leeming and Lucock, 2009).

\section{MATERNAL METHYL SUPPLEMENTED DIETS LIKELY LEAD TO SYSTEMIC EFFECTS}

Select animal model and human epidemiological studies highlight the primary concern with maternal and adult methyl supplemented diet regimens (Tables 1A and B). Methyl-enriched nutritional compounds mediate one-carbon metabolism (Figure 1) and thereby increase the availability of S-adenosylmethionine (SAM). SAM serves as the primary donor of methyl groups to a wide range of biomolecules, including nucleic acids and histone proteins. Therefore, it is not possible with this dietary approach to target specific biomolecules for prevention and remediation strategies. In some cases, these diets might induce hypermethylation and suppression of harmful sites, such as embedded retroelements and proto-oncogenes. However, tumor suppressor and other disease-suppressing genes might also become entrapped in this DNA methylation "net" and transcriptionally silenced. In other words, tinkering with methylation status on the global level, as likely occurs with consumption of methyl supplements, can affect both "beneficial" and "harmful" genes. The scale of disease promotion or prevention is likely tipped one way or another depending on the combined genes that are affected. 
Table 1A | Animal model studies linking maternal MS diets and effects on offspring health and disease.

\begin{tabular}{|c|c|c|c|}
\hline Publication & Animal model & Dosing regimen & Major findings \\
\hline $\begin{array}{l}\text { Dolinoy et al., } \\
2007\end{array}$ & $\begin{array}{l}\text { a/a and } A^{v y} / a \\
\text { mice }\end{array}$ & $\begin{array}{l}\text { Two weeks prior to mating and throughout } \\
\text { gestation and lactation, a/a female mice carrying } \\
A^{v y} / a \text { mice offspring were fed an AIN93G, AIN93G } \\
\text { + bisphenol A ( } 50 \mathrm{mg} \text { BPA } / \mathrm{kg} \text { feed weight) or AIN } \\
93 \mathrm{G} \text { diet supplemented with BPA ( } 50 \mathrm{mg} / \mathrm{kg} \text { feed } \\
\text { weight) and methyl supplemented (MS, including } \\
4.3 \mathrm{mg} \text { of folic acid } / \mathrm{kg} \text { feed weight, } 0.53 \mathrm{mg} \text { of } \\
\text { vitamin B } 12 / \mathrm{kg} \text { feed weight, } 5 \mathrm{~g} \text { of betaine } / \mathrm{kg} \text { feed } \\
\text { weight, and } 7.97 \mathrm{~g} \text { of choline chloride } / \mathrm{kg} \text { feed }\end{array}$ & $\begin{array}{l}\text { Those females exposed to the BPA diet alone were } \\
\text { reported to give birth to greater percentage of } \\
\text { yellow coat color } A^{v y} / a \text { offspring, who are prone to } \\
\text { developing metabolic disorders. In contrast, } \\
\text { females exposed to the combined diet gave birth } \\
\text { to equivalent percentage of brown to yellow coat } \\
\text { color } A^{v y} / a \text { offspring, suggesting that the maternal } \\
\text { MS diet abolished the harmful effects of BPA in } \\
\text { this epigenetic animal model. }\end{array}$ \\
\hline
\end{tabular}

$\begin{array}{ll}\text { Wolff et al., } & \text { a/a and } A^{v y} / a \\ \text { 1998; Cooney } & \text { mice }\end{array}$

et al., 2002 weight) diet.

The a/a dams were placed on a control (NIH-31 diet) 3SZM diet 2 weeks prior to mating to $A^{v y} / a$ males and through parturition. Those receiving the methyl supplemented diet were then divided into those that received the MS diet for 1 week after birth followed by a lower dose of methyl supplements (HS diet) for the second week after birth and the NIH-31 thereafter. Other dams were placed on the MS diet 2 weeks prior to mating, HS diet for 1 week after birth followed by the $\mathrm{NIH}-31$ thereafter. Methyl components in the 3SZM diet included: $15 \mathrm{~g}$ choline, $15 \mathrm{~g}$ betaine, $15 \mathrm{mg}$ folic acid, $1.5 \mathrm{mg}$ vitamin B12, $7.5 \mathrm{mg}$ L-methionine, and $150 \mathrm{mg}$ zinc. MS diet included $5 \mathrm{~g}$ choline, $5 \mathrm{~g}$ betaine, $5 \mathrm{mg}$ folic acid, and $0.5 \mathrm{mg}$ vitamin $\mathrm{B}_{12}$. Those in the HS diet included: $2.5 \mathrm{~g}$ choline, $2.5 \mathrm{~g}$ betaine, $2.5 \mathrm{mg}$ folic acid, and $0.25 \mathrm{mg}$ vitamin $\mathrm{B}_{12}$.
The combined studies indicated that maternal MS of a/a mice carrying $A^{v y} / a$ offspring increases the DNA methylation status of long terminal repeat (LTR) controlling agouti ( $A$ ) expression and thereby, increasing the percentage of pseudoagouti coat color relative to yellow coat color $A^{v y} / a$ offspring with the former generally remaining healthy throughout their lifespan.

$\begin{array}{lll}\begin{array}{l}\text { Waterland and } \\ \text { Jirtle, } 2003\end{array} \quad \text { mice and } A^{v y} / a & \text { The a/a females were placed on a control (NIH-31) } \\ & \text { or NIH-31 diet supplemented with methyl } \\ & \text { donors/cofactors (same as in Wolff et al., 1998) } 2 \\ & \text { weeks prior to mating to } A^{v y} / a \text { males and } \\ & \text { throughout gestation and lactation. }\end{array}$

Cropley et al., $\quad$ a/a and $A^{v y} / a$
2012 mice

Two weeks prior to breeding and through weaning of the $\mathrm{F}_{5}$ generation, $A^{v y} / a$ males and a/a females were placed on a control $(\mathrm{NIH}-31)$ or this diet supplemented with methyl donors/cofactors: $15 \mathrm{~g}$ choline, $15 \mathrm{~g}$ betaine, $7.5 \mathrm{~g}$ L-methionine, $150 \mathrm{mg}$ $\mathrm{ZnSO}_{4}, 15 \mathrm{mg}$ folic acid, and $1.5 \mathrm{mg}$ vitamin $\mathrm{B}_{12}$. From weaning of $\mathrm{F}_{5}$ generation through $\mathrm{F}_{8}$ generation, all animals were placed on a control (NIH-31) diet.

Two weeks prior to mating initial pair through six
generations, C57BI6J males and females were placed either on a NIH-31 control diet or this diet supplemented with methyl donors/cofactors: $15 \mathrm{~g}$ choline, $15 \mathrm{~g}$ betaine, $7.5 \mathrm{~g}$ L-methionine, $150 \mathrm{mg}$ zinc, $15 \mathrm{mg}$ folic acid, and $1.5 \mathrm{mg}$ vitamin $\mathrm{B}_{12}$.

\begin{tabular}{lll}
\hline Billington & Mice deficient & Females carrying mice deficient in this gene were \\
et al., 2013 & for twisted & fed a control (NIH-31) or MS diet that included \\
& gastrulation & folate, vitamin $\mathrm{B}_{12}$, choline, and betaine (Harlan \\
& (Twsg1) & Teklad-TD.01308) 2 weeks prior to mating and \\
& throughout gestation and lactation.
\end{tabular}

Li et al., $2011 \quad$ C57BI6J
These finding supported the earlier work of Wolff et al., 1998; Cooney et al., 2002 in that that it showed that MS to a/a carrying $A^{v y} / a$ offspring increased the percentage of pseudoagouti offspring by increasing the $\mathrm{CpG}$ methylation of the $A^{v y}$ locus.

MS increased proportion of pseudoagouti offspring through the $F_{5}$ generation. However, removal of the MS diet in the $F_{5}$ generation resulted in a return to the distribution of pseudoagouti to brown coat color $A^{v y} / a$ mice, suggesting that the epigenetic status of the germline of $A^{v y}$ are reversible after MS removal.
MS increased the stochastic epigenetic variation in several loci with the effects becoming more pronounced in later generations.
These transgenic deficient mice generally demonstrate midline facial and jaw defects. However, maternal MS exposure prevented the jaw but not midline defects in these mice. 
Table 1A | Continued

\begin{tabular}{|c|c|c|}
\hline Publication & Animal model & Dosing regimen \\
\hline $\begin{array}{l}\text { Delaney et al., } \\
2013\end{array}$ & $\begin{array}{l}\text { ApoE } \\
\text { homozygous } \\
\text { mutant mice }\end{array}$ & $\begin{array}{l}\text { Females carrying these transgenic mutant mice } \\
\text { were fed a control or MS (11.8 g/kg L-methionine, } \\
13.5 \mathrm{mg} / \mathrm{kg} \text { folic acid, } 1560 \mathrm{mg} / \mathrm{kg} \mathrm{B} \mathrm{B}_{12}, 0.72 \mathrm{~g} / \mathrm{kg} \\
\mathrm{ZnSO}_{4} .7 \mathrm{H}_{2} \mathrm{O}, 0.015 \mathrm{~g} / \mathrm{kg} \text { betaine, and } 19.4 \mathrm{~g} / \mathrm{kg} \\
\text { choline chloride) diet } 3 \text { weeks prior to mating and } \\
\text { throughout gestation and lactation. At weaning, all } \\
\text { males were placed on a } 42 \% \text { high fat diet (HFD) } \\
\text { until they were euthanized. }\end{array}$ \\
\hline
\end{tabular}

\begin{tabular}{|c|c|c|}
\hline $\begin{array}{l}\text { Ash et al., } \\
2014\end{array}$ & $\begin{array}{l}\text { Ts65Dn female } \\
\text { mice (a mouse } \\
\text { model for down } \\
\text { syndrome and } \\
\text { Alzheimer's } \\
\text { disease) and } \\
\text { C57/Bl6J Eicher } \\
\text { X C3H/HeSnJ F1 } \\
\text { male mice. }\end{array}$ & $\begin{array}{l}\text { Breeder pairs were randomly assigned to a control } \\
\text { chow-based diet (AIN-76A containing } 1.1 \mathrm{~g} / \mathrm{kg} \\
\text { choline chloride or a choline-supplemented diet } \\
\text { (AIN-76A with } 5.0 \mathrm{~g} / \mathrm{kg} \text { choline chloride). Weaned } \\
\text { pups were placed on the control diet. }\end{array}$ \\
\hline
\end{tabular}

\begin{tabular}{ll}
\hline Medici et al., & C3H and tx-j \\
2014 & mice
\end{tabular}

\section{Major findings}

The maternal MS exposure alleviated the atherosclerosis that would otherwise occur in these mice. Correspondingly, those exposed to the diet regimen had inhibition of T lymphocyte expression of $\mathrm{Ccr} 2$, reduction in other inflammatory cytokines, and increased circulating HDL to LDL ratio.
- Spatial mapping was compromised in control Ts65Dn mice relative normal disomic (2N) littermates. However, maternal choline supplementation improved spatial mapping of Ts65Dn mice.

- Ts65Dn mice possessed decreased number and density of medial septal hippocampal basal forebrain cholinergic neurons (BFCNs) in control Ts65Dn mice relative disomic littermates. Maternal chonine supplementation increased the numbers of these neurons.

Maternal choline supplementation of $\mathrm{C} 3 \mathrm{H}$ dams prevented transcriptional deficits and reduced body weight at weaning observed in their $t x-j$ offspring. gestation (GD17) a control $(8 \mathrm{mmol} / \mathrm{kg}$ choline of diet) or choline supplemented $(36 \mathrm{mmol} / \mathrm{kg}$ choline of diet). Other foster $\mathrm{C} 3 \mathrm{H}$ females received these same diets that extended through lactation (21 days postpartum).

Carlin et al., $\quad$ C57BL/6J mice
2013

Bred female mice were exposed to a control ( $18.5 \%$ protein, $12 \%$ fat and $69.5 \%$ carbohydrate), methyl supplemented ( $15 \mathrm{~g}$ choline chloride, $15 \mathrm{~g}$ betaine [anhydrous], $15 \mathrm{mg}$ folic acid, $1.5 \mathrm{mg}$ vitamin $\mathrm{B}_{12}, 7.5 \mathrm{~g}$ L-methionine, and $150 \mathrm{mg}$ zinc from $\left.\mathrm{ZnSO}_{4} / 7 \mathrm{H}_{2} \mathrm{O}\right)$, high fat $(\mathrm{HF}, 18.5 \%$ protein, $60 \%$ fat, and $20.5 \%$ carbohydrate) diet alone, or a combination of a HF and MS diet (maternal obesogenic methyl-supplemented, MOM diet) throughout gestation and lactation.

Downing C57BL/6J mice
et al., 2011
Two weeks before mating, dams were placed on an NIH-31 control diet or the 3SZM diet (Wolff et al., 1998) containing $15 \mathrm{~g}$ choline, $15 \mathrm{~g}$ betaine, $15 \mathrm{mg}$ folic acid, $1.5 \mathrm{mg}$ Vitamin $\mathrm{B}_{12}, 7.5 \mathrm{~g}$ L-methionine, and $150 \mathrm{mg}$ zinc. Control and MS dams were treated with $5.8 \mathrm{~g} / \mathrm{kg}$ ethanol on gestational day 9 .
The methyl supplements in this diet regimen mitigated the harmful metabolic, behavioral, DNA methylation, and gene expression effects of the high fat component.
- Gestational exposure to ethanol reduced offspring expression of lgf2.

- Prior and concurrent exposure to a maternal MS diet abolished these ethanol-induced alterations in lgf2 expression.

- Maternal MS decreased prenatal mortality, enhanced prenatal growth, and reduced the incidence of digit malformations.

\begin{tabular}{lll}
\hline Giudicelli & Sprague Dawley & Female rats were fed a control or MS $(12 \mathrm{~g} / \mathrm{kg}$ \\
et al., 2013 & Rats & L-methionine, $15 \mathrm{~g} / \mathrm{kg}$ choline, $15 \mathrm{~g} / \mathrm{kg}$ betaine, \\
& $1000 \mathrm{mg} / \mathrm{kg}$ vitamin $\mathrm{B}_{12}, 15 \mathrm{mg} / \mathrm{kg}$ folic acid, and \\
& $180 \mathrm{mg} / \mathrm{kg}$ zinc) diet 21 to 28 prior to mating and \\
& throughout gestation and lactation.
\end{tabular}

- A maternal MS diet decreased circulating concentrations of leptin and led to hypermethylation of the $\mathrm{Ob}$ promoter in exposed offspring.

- Exposed male offspring showed increased long-term body weight gain.

- Exposed male and female offspring had suppressed post-natal growth. 
Table 1A / Continued

\begin{tabular}{|c|c|c|c|}
\hline Publication & Animal model & Dosing regimen & Major findings \\
\hline $\begin{array}{l}\text { Tsang et al., } \\
2012\end{array}$ & CD1 Mice & $\begin{array}{l}\text { Pregnant mice were fed a control or } 11 \mathrm{mg} / \mathrm{kg} \text { folate } \\
\text { supplemented diet. Some members of both } \\
\text { groups were then subjected from gestational day } \\
\text { (GD)1 to GD18 to water containing Arsenic (As, } 85 \\
\text { ppm). }\end{array}$ & $\begin{array}{l}\text { Mouse fetuses at GD18 exposed to a maternal diet } \\
\text { containing arsenic and MS demonstrated more } \\
\text { pronounced hepatic DNA methylation changes and } \\
\text { impaired fetal development and body weight gain } \\
\text { compared to those exposed to the maternal } \\
\text { arsenic-supplemented diet alone. }\end{array}$ \\
\hline
\end{tabular}

Huang et al., $\quad$ C57BL/6J Mice
2014

2014
Female mice were placed on a control folic acid $2 \mathrm{mg}$ folic acid/ kg diet, AIN93G) diet, or this same diet with the recommended folic acid supplement (5 mg folic acid/kg diet, RFOIS) or high folic acid (40 mg folic acid/kg diet, HFolS) before and after pregnancy. At birth, all dams were switched to the AIN93G control diet, and male weanling pups were placed on this same diet. Some male offspring were euthanized at 7 weeks of age; whereas, the remaining males per group were switched to a high fat diet until they were euthanized at 15 weeks of age.

Schaible et al., $\quad$ C57BL/6J Mice 2011
Females were exposed to a control (NIH-31) or this diet supplemented with methyl components $(5 \mathrm{mg} / \mathrm{kg}$ folic acid; $0.5 \mathrm{~g} / \mathrm{kg}$ vitamin B12; $5 \mathrm{~g} / \mathrm{kg}$ betaine; and $5.76 \mathrm{~g} / \mathrm{kg}$ choline [TD\#01308, Harlan-Teklad]) 2 weeks prior to mating and throughout gestation and lactation.
- No differences were detected in males from the various groups euthanized prior to being exposed a high fat diet.

- After 8 weeks of being on the high fat diet, males derived from dams on the HfolS diet had increased incidence of obesity, glucose intolerance, and insulin resistance relative to controls.

- Hfols sons exhibited reduced serum adiponectin concentrations and corresponding decrease in adiponectin (AdipoQ) mRNA expression but increased global DNA hypermethylation in white adipose tissue compared to control males.

A maternal MS diet led to:

- Harmful and persistent changes in the offspring gut microbiota.

- Offspring colonic mucosal DnA methylation and gene expression changes.

- Increased incidence of colitis in exposed compared to control offspring.

Maternal methyl supplementation increased the incidence of allergic airway disease in her offspring with corresponding hypermethylation of Runx3, a gene that has previously been shown to suppresses allergic airway disease.

Hollingsworth C57BL/6J mice
et al., 2008

Delaney et al., C57BL/6J mice 2013
Two weeks prior to mating and throughout pregnancy, females were placed on an NIH-31 control diet or AIN93G diet supplemented with methyl donors and cofactors (folic acid, Vitamin $\mathrm{B}_{12}$, choline chloride, betaine, and $\mathrm{ZnSO}_{4} \times 7 \mathrm{H}_{2} \mathrm{O}$ for a low methyl diet and a high methyl diet concentrations not specified in paper and reference Supplemental Table 1 is not included on the journal's website). F1 progeny were placed on the NIH-31 control diet
Three weeks prior to mating, females were placed on a NIH-31 control or a maternal methyl-supplemented diet $(13.5 \mathrm{mg} / \mathrm{kg}$ folic acid, Vitamin $B_{12} 1.56 \mathrm{~g} / \mathrm{kg}, 15 \mathrm{mg} / \mathrm{kg}$ betaine, and $19.4 \mathrm{~g} / \mathrm{kg}$ choline chloride). Weaned pups were either euthanized at 28 days of age or placed on the control diet
- F1 offspring exposed to the maternal MS were smaller in size at 28 days of age compared to controls.

- T-cells from the maternal MS offspring possessed increased DNA methylation relative to those from control mice.

- T cells from maternal MS mice exhibited reduced T cell chemokine receptor (Ccr2 and Ccr5), C-X-Cchemokine receptor 3, Tnfa, and //4 gene expression and associated decreased chemotaxis.

A maternal MS (choline) or choline deficient diet resulted in selective epimutations in DNA methylation and histone protein marks.

\begin{tabular}{lll}
\hline Davison et al., & Sprague Dawley & Female rats were fed a control $(8 \mathrm{mmol} / \mathrm{kg}$ choline \\
2009 & Rats & $\begin{array}{l}\text { chloride), choline-supplemented (36 mmol } / \mathrm{kg} \\
\text { choline chloride), or choline-deficient }(0 \mathrm{mmol} / \mathrm{kg} \\
\text { choline chloride) diet from GD11 to GD17 }\end{array}$
\end{tabular}

Barua et al., C57BI6J Gestational and post-natal exposure (in case of pup 2014
Gestational and post-natal exposure (in case
assessments) to control diet, $0.4 \mathrm{mg}$ folic acid-supplemented diet (lower dose), or $4 \mathrm{mg} / \mathrm{kg}$ folic acid-supplemented diet (higher dose)
Higher folic acid-supplemented diet led to: - Disruptive gene and protein expression changes in the cerebral hemispheres of newborn pups - Behavioral abnormalities in neonatal pups, including increased ultrasonic vocalizations, anxiety-like, and hyperactive behaviors. 
Table 1B | Human epidemiological studies linking maternal MS diets and effects on offspring health and disease.

\begin{tabular}{lll}
\hline Publication & Study population/design & Major findings \\
\hline Boeke et al., 2012 & $\begin{array}{ll}\text { Determination of various maternal MS, including choline, } \\
\text { and offspring umbilical cord methylation. }\end{array}$ & $\begin{array}{l}\text { Increased maternal intake during the periconceptional } \\
\text { period of choline was inversely correlated with umbilical } \\
\text { cord methylation in sons but not daughters. }\end{array}$ \\
\hline
\end{tabular}

Haggarty et al., $2013 \quad$ Measurement of folic acid supplements during various gestational periods, including after 12 weeks of gestation, and measurements of epigenetic changes in offspring umbilical cord blood and methylation status of individual imprinted genes and repeat elements.
Increased consumption of folic acid supplements by pregnant women after 12 weeks of gestation was linked to epigenetic changes in fetal core blood, including increased methylation of the paternal copy of IGF2 and decreased methylation of the paternally-imprinted PEG3, as well as repeat elements (LINE-1s).

\begin{tabular}{|c|c|}
\hline Kim et al., 2014 & $\begin{array}{l}\text { A retrospective secondary analysis cohort population } \\
\text { consisting of Korean mother and children dyads was } \\
\text { examined. Pregnancies ( } 215 \text { included in the study) were } \\
\text { delivered at Korea University Anam Hospital between July } \\
\text { 1, } 2009 \text { and June 13, 2010. Maternal folate level was } \\
\text { measured with an I'125-based RIA. }\end{array}$ \\
\hline
\end{tabular}

Veeranki et al., $2014 \quad$ A retrospective cohort study that included 167,333 women (15-44) and their biological infants born during 1995-2007 that were enrolled in the Tennessee Medicaid program (TennCare) was used for these studies. Infants were tracked for bronchiolitis in the first year of life.
Incidence of preeclamsia and small for gestational age births was reduced in folic acid supplemented group compared to control mothers.
Dominguez-Salas et al.,
2014

Gambian women and their children representing 24 villages and 166 women were included in this 2 years study that examined consumption of maternal methyl donors and DNA methylation pattern in the offspring genomes.
Study included children that ranged from 24 to 60 months of age ( $N=288$ ) and examined effects of maternal consumption of prenatal vitamins containing methyl components during the periconceptional period and offspring incidence of ASD.
Maternal supplementation of folic acid through prenatal vitamins beginning at the first trimester increased the likelihood of infant bronchiolitis
Schmidt et al., 2011
Measurement of folic acid intake during the periconceptional period and ASD risk in mothers and children, including those that had inefficient folate metabolism due to a single nucleotide polymorphism (SNP) in the methyhlenetetrahydrofolate reductase enzyme (MTHFR 677 C>T variant genotype).

Schmidt et al., $2012 \quad$ Measurement of folic acid intake during the
periconceptional period and ASD risk in mothers and
children, including those that had inefficient folate
metabolism due to a single nucleotide polymorphism (SNP)
in the methyhlenetetrahydrofolate reductase enzyme
(MTHFR 677 C $>$ T variant genotype).

Beard et al., 2011
Rochester Epidemiological Project, Rochester, MN study that spanned 1976-1997 and examined ASD incidence rates relative to maternal consumption of folic acid.
There was a strong association between maternal methyl donor supplementation and potentially harmful DNA methylation alterations in offspring genomes.

Increased risk for autism spectrum disorders (ASD) was identified in children whose mothers did not consume prenatal vitamins supplemented with methyl components during the periconceptional period.
Consumption of folic acid by women beginning at the periconceptional period was associated with reduced risk of ASD in mothers and children with inefficient folate metabolism.

\begin{abstract}
A strong correlation (0.87) was evident for maternal consumption of prescription prenatal vitamins (containing $>1 \mathrm{mg}$ folic acid) and ASD incidence in offspring.
\end{abstract}

\section{OTHER FACTORS INFLUENCING THE EPIGENETIC EFFECTS OF MATERNAL METHYL SUPPLEMENTED DIETS}

Genetic variation and other maternal factors may be important considerations in determining whether specific nutraceuticals are beneficial. It is clear that there are gene-nutrient interactions in one-carbon metabolism (Friso and Choi, 2005). As noted, maternal folate supplementation may help to reduce the incidence of ASD in mothers and children with a MTHFR $677 \mathrm{C}>\mathrm{T}$ variant genotype that leads to inefficient folate metabolism. In contrast, this same diet may increase the risk for ASD in those with normal folate metabolism (Rogers, 2008; Leeming and Lucock, 2009;
Beard et al., 2011). Similarly, total intake of choline and maternal genotype in the MTHFR and phosphatidyl ethanolamine methyltransferase (PEMT) enzymes interact to alter the amount of choline and choline metabolites in the breast milk, and thereby the amount of total choline available to the developing infant (Fischer et al., 2010a). In mothers with genetic polymorphisms that alter the intake-metabolite concentrations, supplemental choline might be beneficial. Maternal estrogen concentrations and gut microbiota populations may also influence the requirement for choline supplementation (Fischer et al., 2010b; Spencer et al., 2011). 
It is possible that not all methyl donors lead to similar epigenetic effects across target organs, tissues, and or cell types (as Reviewed in Ly et al., 2012). For example, diet duration and potential interactions with other dietary components may be confounding factors. While an in-depth comparison is not currently possible due to limited studies assessing individual methyl components, Table 1A provides details on the treatment strategies for the animal experiments detailed herein. As shown in this Table, considerable variations in concentrations of methyl donors alone and in combination with each other have been tested in the different rodent studies. Future experiments need to be designed to consider the safety of single nutrient vs. nutrient combinations and a range of doses for each supplement should be tested.

Concurrent exposure to other compounds may also influence the effects of a methyl supplemented diet. For instance, prenatal exposure to exogenous glucocorticoids alters placental transport, and subsequently the availability of methyl donors, with an increased transfer of folate; whereas, choline transport across this organ was suppressed (Wyrwoll et al., 2012). Correspondingly, reduced fetal plasma methionine levels were observed in the glucocorticoid exposed fetuses.

Sexually dimorphic differences might also occur in response to in utero or adult exposure to methyl supplemented diets, as has been reported for other diets (Mao et al., 2010). For example, both maternal folate supplementation and fetal sex influence the DNA methylation status of Slc394a in the intestinal tract (McKay et al., 2011). Similarly, maternal methyl-deficient diets selectively result in metabolic disturbances in male, but not female, rat offspring (Maloney et al., 2011). A diet deficient in key methyl donors (choline and methionine) has been linked with hepatic carcinogenesis in F344 male rats (Mikol et al., 1983; Wilson et al., 1984; Pogribny et al., 2006); whereas, these dietary deficiencies do not result in liver cancer in their female counterparts (Saito et al., 1991).

Lastly, methyl components may lead to tissue/cell-specific effects. Such differences would suggest that these diets might aide in disease prevention in select organs or tissues but also exacerbate disease risk in others. To our knowledge, however, there has not currently been a comprehensive examination of how a maternal MS diet affects varying tissues and somatic/germ cells, and thus impacted phenotypes. This information is critical in determining the global effects that might be anticipated in offspring born to mothers on these supplemented diets.

\section{CONCLUSIONS AND FUTURE DIRECTIONS}

The notion that "optimal" MS diets might be used for prevention and remediation strategies to treat various human diseases is gaining currency (Van Den Veyver, 2002). Mounting studies have reported on effects of maternal MS diets in animal models and human epidemiological studies. However, there is currently no consensus on whether these dietary regimens are actually protective against a range of diseases. While early reports suggested that these diets might be useful in prevention strategies in epigenetic and transgenic animal models (Dolinoy et al., 2007; Billington et al., 2013; Delaney et al., 2013; Giudicelli et al., 2013), subsequent studies in animal models have suggested that maternal MS diets result in widespread epimutations that may govern diverse diseases (Hollingsworth et al., 2008; Schaible et al., 2011; Tsang et al., 2012). Additionally, maternal MS diets may alter the DNA methylation of a myriad of genes, including repetitive elements and imprinted genes in humans (Haggarty et al., 2013; Dominguez-Salas et al., 2014). The extent of such epimutations, and their biological consequences, remain to be determined.

While the idea of an "optimal" maternal MS diet preventative/treatment strategy is appealing, this diet approach cannot be used to target selectively a single gene. Instead, indiscriminate and potentially irreversible methylation changes in a broader range of biomolecules and cells/tissues may result from such dietary treatment. Potential disease outcomes are likely tipped one way or another depending on the fetal sex, maternal/fetal genetic background, other maternal factors (such as endogenous and exogenous circulating hormones and the intestinal microbiome), as well as tissue/cell specificity and concentration and duration of exposure to these nutritional supplements. All of these factors should be considered when employing maternal MS diets to combat fetal disease.

Comprehensive long term animal and human epidemiological studies should be undertaken to assess the global effects of these nutraceuticals and to resolve the current conflicting data in regards to maternal MS diet. Until then, women requesting prenatal/perinatal vitamin support should be advised against consuming methyl supplements, (e.g., folic acid) in doses that exceed the current recommendations for preventing fetal neural tube defects.

\section{REFERENCES}

Ash, J. A., Velazquez, R., Kelley, C. M., Powers, B. E., Ginsberg, S. D., Mufson, E. J. et al. (2014). Maternal choline supplementation improves spatial mapping and increases basal forebrain cholinergic neuron number and size in aged Ts65Dn mice. Neurobiol. Dis. 70C, 32-42. doi: 10.1016/j.nbd.2014.06.001

Barker, D. J. (1997). Maternal nutrition, fetal nutrition, and disease in later life. Nutrition 13, 807-813.

Barouki, R., Gluckman, P. D., Grandjean, P., Hanson, M., and Heindel, J. J. (2012). Developmental origins of non-communicable disease: implications for research and public health. Environ. Health 11:42. doi: 10.1186/1476-069x-11-42

Barua, S., Chadman, K. K., Kuizon, S., Buenaventura, D., Stapley, N. W., Ruocco, F., et al. (2014). Increasing maternal or post-weaning folic Acid alters gene expression and moderately changes behavior in the offspring. PLOS ONE 9:e101674. doi: 10.1371/journal.pone.0101674

Beard, C. M., Panser, L. A., and Katusic, S. K. (2011). Is excess folic acid supplementation a risk factor for autism? Med. Hypotheses 77, 15-17. doi: 10.1016/j.mehy.2011.03.013

Billington, C. J. Jr., Schmidt, B., Zhang, L., Hodges, J. S., Georgieff, M. K., Schotta, G., et al. (2013). Maternal diet supplementation with methyl donors and increased parity affect the incidence of craniofacial defects in the offspring of twisted gastrulation mutant mice. J. Nutr. 143, 332-339. doi: 10.3945/jn.112.168906

Boeke, C. E., Baccarelli, A., Kleinman, K. P., Burris, H. H., Litonjua, A. A., RifasShiman, S. L., et al. (2012). Gestational intake of methyl donors and global LINE-1 DNA methylation in maternal and cord blood: prospective results from a folate-replete population. Epigenetics 7, 253-260. doi: 10.4161/epi.7.3.19082

Carlin, J., George, R., and Reyes, T. M. (2013). Methyl donor supplementation blocks the adverse effects of maternal high fat diet on offspring physiology. PLoS ONE 8:e63549. doi: 10.1371/journal.pone.0063549

Cooney, C. A., Dave, A. A., and Wolff, G. L. (2002). Maternal methyl supplements in mice affect epigenetic variation and DNA methylation of offspring. J. Nutr. 132, 2393S-2400S.

Cropley, J. E., Dang, T. H., Martin, D. I., and Suter, C. M. (2012). The penetrance of an epigenetic trait in mice is progressively yet reversibly increased by selection and environment. Proc. Biol. Sci. 279, 2347-2353. doi: 10.1098/rspb.2011.2646 
Davison, J. M., Mellott, T. J., Kovacheva, V. P., and Blusztajn, J. K. (2009). Gestational choline supply regulates methylation of histone $\mathrm{H} 3$, expression of histone methyltransferases $\mathrm{G} 9 \mathrm{a}(\mathrm{Kmtlc})$ and Suv39h1 (Kmtla), and DNA methylation of their genes in rat fetal liver and brain. J. Biol. Chem. 284, 1982-1989. doi: 10.1074/jbc.M807 651200

Delaney, C., Garg, S. K., Fernandes, C., Hoeltzel, M., Allen, R. H., Stabler, S., et al. (2013). Maternal diet supplemented with methyl-donors protects against atherosclerosis in F1 ApoE(-/-) mice. PLoS ONE 8:e56253. doi: 10.1371/journal.pone. 0056253

Delaney, C., Hoeltzel, M., Garg, S. K., Warner, R., Johnson, K., and Yung, R. (2012). Maternal micronutrient supplementation suppresses T cell chemokine receptor expression and function in F1 mice. J. Nutr. 142, 1329-1335. doi: 10.3945/jn.111.155903

Dolinoy, D. C., Huang, D., and Jirtle, R. L. (2007). Maternal nutrient supplementation counteracts bisphenol A-induced DNA hypomethylation in early development. Proc. Natl. Acad. Sci. U.S.A. 104, 13056-13061. doi: 10.1073/pnas.0703739104

Dominguez-Salas, P., Moore, S. E., Baker, M. S., Bergen, A. W., Cox, S. E., Dyer, R. A., et al. (2014). Maternal nutrition at conception modulates DNA methylation of human metastable epialleles. Nat. Commun. 5:3746. doi: 10.1038/ncomms4746

Downing, C., Johnson, T. E., Larson, C., Leakey, T. I., Siegfried, R. N., Rafferty, T. M., et al. (2011). Subtle decreases in DNA methylation and gene expression at the mouse Igf2 locus following prenatal alcohol exposure: effects of a methylsupplemented diet. Alcohol 45, 65-71. doi: 10.1016/j.alcohol.2010.07.006

Fischer, L. M., Da Costa, K. A., Galanko, J., Sha, W., Stephenson, B., Vick, J., et al. (2010a). Choline intake and genetic polymorphisms influence choline metabolite concentrations in human breast milk and plasma. Am. J. Clin. Nutr. 92, 336-346. doi: 10.3945/ajcn.2010.29459

Fischer, L. M., Da Costa, K. A., Kwock, L., Galanko, J., and Zeisel, S. H. (2010b). Dietary choline requirements of women: effects of estrogen and genetic variation. Am. J. Clin. Nutr. 92, 1113-1119. doi: 10.3945/ajcn.2010.30064

Friso, S., and Choi, S. W. (2005). Gene-nutrient interactions in onecarbon metabolism. Curr. Drug Metab. 6, 37-46. doi: 10.2174/1389200052 997339

Giudicelli, F., Brabant, A. L., Grit, I., Parnet, P., and Amarger, V. (2013). Excess of methyl donor in the perinatal period reduces postnatal leptin secretion in rat and interacts with the effect of protein content in diet. PLoS ONE 8:e68268. doi: 10.1371/journal.pone.0068268

Haggarty, P., Hoad, G., Campbell, D. M., Horgan, G. W., Piyathilake, C., and McNeill, G. (2013). Folate in pregnancy and imprinted gene and repeat element methylation in the offspring. Am. J. Clin. Nutr. 97, 94-99. doi: 10.3945/ajcn.112.042572

Hanson, M., and Gluckman, P. (2011). Developmental origins of noncommunicable disease: population and public health implications. Am. J. Clin. Nutr. 94, 1754S-1758S. doi: 10.3945/ajcn.110.001206

Hollingsworth, J. W., Maruoka, S., Boon, K., Garantziotis, S., Li, Z., Tomfohr, J., et al. (2008). In utero supplementation with methyl donors enhances allergic airway disease in mice. J. Clin. Invest. 118, 3462-3469. doi: 10.1172/ JCI34378

Huang, Y., He, Y., Sun, X., He, Y., Li, Y., and Sun, C. (2014). Maternal high folic acid supplement promotes glucose intolerance and insulin resistance in male mouse offspring fed a high-fat diet. Int. J. Mol. Sci. 15, 6298-6313. doi: 10.3390/ijms 15046298

Kim, M. W., Ahn, K. H., Ryu, K. J., Hong, S. C., Lee, J. S., Nava-Ocampo, A. A., et al. (2014). Preventive effects of folic acid supplementation on adverse maternal and fetal outcomes. PLoS ONE 9:e97273. doi: 10.1371/journal.pone.0097273

Leeming, R. J., and Lucock, M. (2009). Autism: is there a folate connection? J. Inherit. Metab. Dis. 32, 400-402. doi: 10.1007/s10545-009-1093-0

Li, C. C., Cropley, J. E., Cowley, M. J., Preiss, T., Martin, D. I., and Suter, C. M. (2011). A sustained dietary change increases epigenetic variation in isogenic mice. PLoS Genet. 7:e1001380. doi: 10.1371/journal.pgen.1001380

Ly, A., Hoyt, L., Crowell, J., and Kim, Y. I. (2012). Folate and DNA methylation. Antioxid. Redox Signal. 17, 302-326. doi: 10.1089/ars.2012.4554

Maloney, C. A., Hay, S. M., Young, L. E., Sinclair, K. D., and Rees, W. D. (2011). A methyl-deficient diet fed to rat dams during the peri-conception period programs glucose homeostasis in adult male but not female offspring. J. Nutr. 141, 95-100. doi: 10.3945/jn.109.119453
Mao, J., Zhang, X., Sieli, P. T., Falduto, M. T., Torres, K. E., and Rosenfeld, C. S. (2010). Contrasting effects of different maternal diets on sexually dimorphic gene expression in the murine placenta. Proc. Natl. Acad. Sci. U.S.A. 107, 5557-5562. doi: 10.1073/pnas.1000440107

McKay, J. A., Wong, Y. K., Relton, C. L., Ford, D., and Mathers, J. C. (2011). Maternal folate supply and sex influence gene-specific DNA methylation in the fetal gut. Mol. Nutr. Food Res. 55, 1717-1723. doi: 10.1002/mnfr.201 100150

Medici, V., Shibata, N. M., Kharbanda, K. K., Islam, M. S., Keen, C. L., Kim, K., et al. (2014). Maternal choline modifies fetal liver copper, gene expression, DNA methylation, and neonatal growth in the tx-j mouse model of Wilson disease. Epigenetics 9, 286-296. doi: 10.4161/epi.27110

Mikol, Y. B., Hoover, K. L., Creasia, D., and Poirier, L. A. (1983). Hepatocarcinogenesis in rats fed methyl-deficient, amino acid-defined diets. Carcinogenesis 4, 1619-1629.

Mynatt, R. L., and Stephens, J. M. (2001). Agouti regulates adipocyte transcription factors. Am. J. Physiol. Cell Physiol. 280, C954-C961.

Pogribny, I. P., Ross, S. A., Wise, C., Pogribny, M., Jones, E. A., Tryndyak, V. P., et al. (2006). Irreversible global DNA hypomethylation as a key step in hepatocarcinogenesis induced by dietary methyl deficiency. Mutat. Res. 593, 80-87. doi: 10.1016/j.mrfmmm.2005.06.028

Rogers, E. J. (2008). Has enhanced folate status during pregnancy altered natural selection and possibly Autism prevalence? A closer look at a possible link. Med. Hypotheses 71, 406-410. doi: 10.1016/j.mehy.2008.04.013

Rosenfeld, C. S. (2010). Animal models to study environmental epigenetics. Biol. Reprod. 82, 473-488. doi: 10.1095/biolreprod.109.080952

Rosenfeld, C. S. (2012). Effects of maternal diet and exposure to bisphenol A on sexually dimorphic responses in conceptuses and offspring. Reprod. Domest. Anim. 47(Suppl. 4), 23-30. doi: 10.1111/j.1439-0531.2012.02051.x

Rosenfeld, C. S., Sieli, P. T., Warzak, D. A., Ellersieck, M. R., Pennington, K. A., and Roberts, R. M. (2013). Maternal exposure to bisphenol A and genistein has minimal effect on $\mathrm{A}(\mathrm{vy}) / \mathrm{a}$ offspring coat color but favors birth of agouti over nonagouti mice. Proc. Natl. Acad. Sci. U.S.A. 110, 537-542. doi: $10.1073 /$ pnas. 1220230110

Saito, R., Palomba, L., Rao, K. N., and Lombardi, B. (1991). Resistance of female Fischer-344 rats to the hepatonecrogenic and hepatocarcinogenic actions of a choline-devoid diet. Carcinogenesis 12, 1451-1457.

Schaible, T. D., Harris, R. A., Dowd, S. E., Smith, C. W., and Kellermayer, R. (2011). Maternal methyl-donor supplementation induces prolonged murine offspring colitis susceptibility in association with mucosal epigenetic and microbiomic changes. Hum. Mol. Genet. 20, 1687-1696. doi: 10.1093/hmg/ddr044

Schmidt, R. J., Hansen, R. L., Hartiala, J., Allayee, H., Schmidt, L. C., Tancredi, D. J., et al. (2011). Prenatal vitamins, one-carbon metabolism gene variants, and risk for autism. Epidemiology 22, 476-485. doi: 10.1097/EDE.0b013e318 $21 \mathrm{~d} 0 \mathrm{e} 30$

Schmidt, R. J., Tancredi, D. J., Ozonoff, S., Hansen, R. L., Hartiala, J., Allayee, H., et al. (2012). Maternal periconceptional folic acid intake and risk of autism spectrum disorders and developmental delay in the CHARGE (CHildhood Autism Risks from Genetics and Environment) case-control study. Am. J. Clin. Nutr. 96, 80-89. doi: 10.3945/ajcn.110.004416

Spencer, M. D., Hamp, T. J., Reid, R. W., Fischer, L. M., Zeisel, S. H., and Fodor, A. A. (2011). Association between composition of the human gastrointestinal microbiome and development of fatty liver with choline deficiency. Gastroenterology 140, 976-986. doi: 10.1053/j.gastro.2010.11.049

Steenblik, J., Schroeder, E., Hatch, B., Groke, S., Broadwater-Hollifield, C., Mallin, M., et al. (2011). Folic acid use in pregnant patients presenting to the emergency department. Int. J. Emerg. Med. 4:38. doi: 10.1186/1865-1380-4-38

Tsang, V., Fry, R. C., Niculescu, M. D., Rager, J. E., Saunders, J., Paul, D. S., et al. (2012). The epigenetic effects of a high prenatal folate intake in male mouse fetuses exposed in utero to arsenic. Toxicol. Appl. Pharmacol. 264, 439-450. doi: 10.1016/j.taap.2012.08.022

Van Den Veyver, I. B. (2002). Genetic effects of methylation diets. Annu. Rev. Nutr. 22, 255-282. doi: 10.1146/annurev.nutr.22.010402.102932

Veeranki, S. P., Gebretsadik, T., Dorris, S. L., Mitchel, E. F., Hartert, T. V., Cooper, W. O., et al. (2014). Association of folic acid supplementation during pregnancy and infant bronchiolitis. Am. J. Epidemiol. 179, 938-946. doi: 10.1093/aje/kwu019

Voisey, J., and Van Daal, A. (2002). Agouti: from mouse to man, from skin to fat. Pigment Cell Res. 15, 10-18. doi: 10.1034/j.1600-0749.2002.00039.x 
Waterland, R. A., Dolinoy, D. C., Lin, J. R., Smith, C. A., Shi, X., and Tahiliani, K. G. (2006). Maternal methyl supplements increase offspring DNA methylation at Axin fused. Genesis 44, 401-406. doi: 10.1002/dvg.20230

Waterland, R. A., and Jirtle, R. L. (2003). Transposable elements: targets for early nutritional effects on epigenetic gene regulation. Mol. Cell. Biol. 23, 5293-5300. doi: 10.1128/MCB.23.15.5293-5300.2003

Wilson, M. J., Shivapurkar, N., and Poirier, L. A. (1984). Hypomethylation of hepatic nuclear DNA in rats fed with a carcinogenic methyl-deficient diet. Biochem. J. 218, 987-990.

Wolff, G. L., Kodell, R. L., Moore, S. R., and Cooney, C. A. (1998). Maternal epigenetics and methyl supplements affect agouti gene expression in Avy/a mice. FASEB J. 12, 949-957.

Wolff, T., Witkop, C. T., Miller, T., and Syed, S. B. (2009a). Folic Acid Supplementation for the Prevention of Neural Tube Defects: an Update of the Evidence for the U.S. Preventive Services Task Force. Evidence Syntheses, No. 70. Rockville, MD: Agency for Healthcare Research and Quality, (US). Report No.: 09-05132-EF-1.

Wolff, T., Witkop, C. T., Miller, T., and Syed, S. B. (2009b). Folic acid supplementation for the prevention of neural tube defects: an update of the evidence for the U.S. Preventive Services Task Force. Ann. Intern. Med. 150, 632-639. doi: 10.7326/0003-4819-150-9-200905050-00010
Wyrwoll, C. S., Kerrigan, D., Holmes, M. C., Seckl, J. R., and Drake, A. J. (2012). Altered placental methyl donor transport in the dexamethasone programmed rat. Placenta 33, 220-223. doi: 10.1016/j.placenta.2011. 12.017

Conflict of Interest Statement: The authors declare that the research was conducted in the absence of any commercial or financial relationships that could be construed as a potential conflict of interest.

Received: 02 June 2014; accepted: 05 August 2014; published online: 26 August 2014. Citation: O'Neill RJ, Vrana PB and Rosenfeld CS (2014) Maternal methyl supplemented diets and effects on offspring health. Front. Genet. 5:289. doi: 10.3389/fgene. 2014.00289

This article was submitted to Epigenomics and Epigenetics, a section of the journal Frontiers in Genetics.

Copyright (C) 2014 O'Neill, Vrana and Rosenfeld. This is an open-access article distributed under the terms of the Creative Commons Attribution License (CC BY). The use, distribution or reproduction in other forums is permitted, provided the original author(s) or licensor are credited and that the original publication in this journal is cited, in accordance with accepted academic practice. No use, distribution or reproduction is permitted which does not comply with these terms. 